\title{
Performance of frost protection structures on yield and post-harvest quality of organically grown winter dawn strawberry
}

\author{
Indore Navnath, R. K. Singh and Harmehar Singh
}

Received : 28.07.2020; Revised : 24.08.2020; Accepted : 26.09.2020

See end of the Paper for authors' affiliation

Correspondence to :

Indore Navnath

AICRP on Plasticulture

Engineering and Technology,

ICAR-CIPHET, Ludhiana

(Punjab) India

Email: indore.sakharam@icar.

gov.in
- ABSTRACT : Low tunnel protected cultivation of organically grown strawberry (winter dawn) was carried out to standardize the cladding material and the height of structure for enhancing the yield and post-harvest quality in Punjab North India. Three different design of low tunnels i.e. three different heights; $45 \mathrm{~cm}, 60 \mathrm{~cm}$ and $75 \mathrm{~cm}$ and three claddings; thin plastic film (50 microns), UV stabilised plastic sheet (200 microns) and non-woven film (20 GSM) were used in the trials. Microclimate parameters, soil moisture and soil temperature inside the installed structures were analyzed throughout the experiments. The maximum yield of crop, number of fruits (45), maximum weight (28g) was observed in the tunnel of size $45 \mathrm{~cm}$ with non-woven 20 GSM followed by UV 200 micron of $60 \mathrm{~cm}$ height and minimum values were observed in other structures and open. All the tunnels maintained favourable soil and canopy temperature for the growth of crop and it was observed that crop grown inside tunnels were protected from any kind of frost injury and exhibited better post-harvest quality than the strawberry grown in open.

KEY WORDS : Frost protection structures, Yield, Post-harvest quality, Organically grown winter dawn strawberry

- HOW TO CITE THIS PAPER : Navnath, Indore, Singh, R.K. and Singh, Harmehar (2020). Performance of frost protection structures on yield and post-harvest quality of organically grown winter dawn strawberry. Internat. J. Agric. Engg., 13(2) : 252-261, DOI: 10.15740/HAS/IJAE/ 13.2/252-261. Copyright@2020: Hind Agri-Horticultural Society. 